\title{
THE PORTACAVAL-SHUNTED RAT: A NEW MODEL FOR THE STUDY OF THE MECHANISMS CONTROLLING VOLUNTARY ETHANOL CONSUMPTION AND ETHANOL PREFERENCE?
}

\section{de Waele J-P, Audet R M, Rose C, Butterworth R F.}

From the Neuroscience Research Unit, André-Viallet Clinical ResearchCenter, Hopital Saint-Luc (Université de Montréal), Montréal, Québec, Canada.

This work was supported by a grant from the Medical Research Council of Canada (PG 11118) (to R.F.B.). J.-P. de Wade is the recipient of a post-doctoral fellowship from the Canadian Liver Foundation.

Reprint requests: Roger F. Butteworth, Ph.D., AndrP- Viallet Clinical Research Center, Hopital Saint-Luc, 10.58 Rue St.Denis, Montréal, Quebec, Canada H2X 3J4.

\section{ABSTRACT}

Portacaval anastomosis (PCA) is a surgical procedure whereby blood from the portal vein is shunted into the inferior vena cava. PCA in the rat results in a significant increase (from $0.77 \pm 0.26$ to $3.51 \pm 0.37 \mathrm{~g}$ of ethanol $/ \mathrm{kg} / \mathrm{day}$ ) in voluntary ethanol consumption in a free- choice paradigm between water and 5\% ethanol solution. After PCA surgery, increased voluntary ethanol consumption starts abruptly at 6 to 7 days and is maintained for $>28$ weeks. Voluntary ethanol consumption in rats after PCA results in blood ethanol levels up to $158 \mathrm{mg} \%$. After PCA, the ethanol preference ratio (defined as the percentage of total fluid intake constituted by ethanol) increased from $19 \pm 2 \%$ to $78 \pm 2 \%$ (p < 0.001 ). Administration of the nonselective opioid receptor antagonist naloxone $(5 \mathrm{mg} / \mathrm{kg}$, sc) resulted in a significant 6 -fold attenuation of voluntary ethanol consumption by rats with PCA, an effect that was not mediated by an effect on locomotor activity. These findings, together with previous reports of wide- spread alterations of the p- and 6-opioid receptors in the brain after PCA, suggest that increased voluntary ethanol consumption and ethanol preference in PCA rats may result from activation of the endogenous opioid system. Preliminary studies suggest that rats with PCA manifest behavioral signs consistent with the development of dependence. The portacaval-shunted rat may provide a useful preparation for the study of mechanisms, in particular those involving the liver, implicated in the development of increased voluntary ethanol consumption and ethanol preference.

Key Words: Ethanol, Preference, Liver, Opioid System, Portacaval Anastomosis.

\section{INTRODUCTION}

CHRONIC LIVER disease of either alcoholic or non-alcoholic etiology invariably results in the formation of portalsystemic shunts as a result of the increase in portal pressure. This portal-systemic shunting frequently results in a complex neuropsychiatric syndrome known as portal- systemic encephalopathy (PSE)(1), with associated changes in brain biochemistry. Increased voluntary ethanol consumption, in a free-choice two-bottle paradigm, has been reported in rats after de Waele J-P, Audet R M, Rose C, Butterworth R F. The portacaval-shunted rat: a new model for the study of the mechanisms controlling voluntary ethanol consumption and ethanol preference? Alcohol Clin Exp Res. 1997-04;21(2):305310 . 
This is a post-peer-review, pre-copyedit version of an article published in Alcohol Clin Exp Res. The final authenticated version is available online at http://dx.doi.org/10.1111/j.1530-0277.1997.tb03765.x

portacaval shunting $(2,3)$ and in rats with carbon tetrachloride(CCL4)-induced cirrhosis4). This finding was surprising, because it is well known that studies of ethanol consumption in the laboratory rat are limited by the innate aversion of rats to ethanol. It is possible that the increase in voluntary ethanol consumption in rats after portacaval shunting may result from alterations in brain biochemistry; such changes include amino acids(6), monoamine $(7,8)$, or opioid peptides. $(9,10)$ With regard to the latter, there is substantial evidence to suggest that the endogenous opioid system of the brain is one of the major neuronal systems involved in the media- tion of increased ethanol consumption. Similarities exist between some of the physiological effects of ethanol and opiates.(11) Administration of nonselective opiate antagonists, such as naloxone(1214 ) and naltrexone (12-14) and of the selective $\delta$-opioid receptor antagonists IC1-174864 (15) and naltrindole(16) lead to reductions in voluntary ethanol consumption in rodents. Furthermore, naltrexone has been used in clinical studies for the treatment of ethanol dependence in humans $(17,18)$. Ethanol stimulates the in vitro release of $\beta$-endorphin $(\beta$-EP) from rat pituitary(19) and hypothalamic(20) preparations, and differences in hypothalamic $\beta$-EP release have been demonstrated between ethanol- preferring and ethanol-avoiding strains and lines of animal(21-23).

Previous studies have revealed alterations of the endogenous opioid system in patients with liver disease $(24,25)$ and in an animal model of PSE (26) as well as in CC14,-induced cirrhosis(27). Recently, we reported that portacaval anastomosis (PCA) in the rat induces alterations in the $\beta$-EP system of the brain, as well as in $\mu$ - and $\delta$-opioid receptors(10). Four weeks after PCA surgery, quantitative autoradiographic studies using selective radioligands revealed that ethanol-naive PCA rats manifest significant changes in the densities of opioid binding sites in nuclei of the limbic system known to modulate the rewarding and the positive- reinforcing effects of many drugs of abuse, including ethanol(18). The aim of the present study was to characterize further the increase in voluntary ethanol consumption by rats after PCA. Ethanol consumption, in a freechoice paradigm be- tween 5\% ethanol and water, was monitored before and after either PCA or sham operation (control). The time come of the development of ethanol preference with respect to PCA surgery time and with respect to day time and night time activity patterns was also assessed. To evaluate the implication of the endogenous opioid system in the increased voluntary ethanol consumption by PCA rats, effects of the opioid antagonist naloxone was studied on both ethanol intake and locomotor activity. Preliminary assessment of dependence on ethanol was made by monitoring relapse to ethanol consumption after episodes of withdrawal.

\section{MATERIALS AND METHODS}

Male Sprague-Dawley rats weighing 250 to $300 \mathrm{~g}$ (Charles River, St.-Constant, Québec) were housed singly under a 12-hr light/dark cycle (lights on at 06:00 AM and lights off at 06:00 PM), with food (Purina Lab Chow) and water available ad libitum. After a 24-hr acclimatization period, the animals were given the choice between two identical drinking bottles: one containing $100 \mathrm{ml}$ of tap water and the other containing $100 \mathrm{mI}$ of a $5 \%$ ethanol solution, made up of $95 \%$ ethanol diluted with tap water. The two drinking bottles were surrounded by food pellets to avoid any food-related preference bias. For similar reasons, the position of the two drinking bottles in the home cage was changed every day. The volume of liquid consumed and the animals' body weight were monitored daily.

After 2 weeks of ethanol exposure, rats underwent a laparotomy under halothane anesthesia, and an end-to-side portacaval anastomosis was performed as previously decribed.(29). Surgery time was under $15 \mathrm{~min}$. For sham operation, after laparotomy, the portal vein and vena cava were clamped for $15 \mathrm{~min}$. Animals were returned to their home cage with food available ad libitum and the choice between water and the 5\% ethanol solution. Body weight, as well as water and ethanol consumption, were monitored daily for a period of 5 weeks postsurgery. Six weeks after PCA surgery, the concentration of the ethanol solution was increased to $10 \%$ for the PCA rats.

\section{ACUTE EFFECTS OF NALOXONE ON ETHANOL CONSUMPTION}

The effects of naloxone were studied after 5 weeks of voluntary $5 \%$ ethanol consumption by PCA rats versus sham-operated controls. Ethanol and water were presented in a two-bottle free-choice paradigm, with food and liquid available ad libitum. de Waele J-P, Audet R M, Rose C, Butterworth R F. The portacaval-shunted rat: a new model for the study of the mechanisms controlling voluntary ethanol consumption and ethanol preference? Alcohol Clin Exp Res. 1997-04;21(2):305310. 
Before the administration of either saline or naloxone, ethanol consumption was monitored on consecutive days between 06:00 and 09:00 PM and between 09:00 and 11:00 PM (lights-off period). NaIoxone-HCI (Sigma Chemical Co., St. Louis, MO) was diluted in sterile saline to afford a stock solution of $50 \mathrm{mg}$ naloxone $/ \mathrm{ml}$. The stock solution was diluted with saline and administered subcutaneously at a final dose of $5 \mathrm{mg}$ of naloxone $/ \mathrm{kg}$ of body weight. The day before naloxone administration, animals were administered an equivalent volume of sterile saline subcutaneously to control for the effects of injection stress. Ethanol consumption was monitored for 180 and $300 \mathrm{~min}$ after the administration of saline or naloxone, and compared with ethanol consumption measured in the absence of either saline or naloxone.

BEHAVIORAL TESTING

Animals were transferred to an isolated room equipped with an Opto-Varimex activity monitor coupled to an Auto-Track system (Columbus Instruments, Columbus, $\mathrm{OH}$ ) for a period of five consecutive days, under a 12-hr light cycle (lights on at 06:00 AM and lights off at 06:00 PM), with food, water, and 5\% ethanol available ad libitum. Locomotor activity of the animals was monitored during the lights-off period on each day. The activity of the animals measured on days 2 and 3 was used to define the normal (baseline) of the animals. On day 4, just before the onset of the lights-off period, rats were administered a single injection of saline, whereas on day 5 , they received a single injection of naloxone $(5 \mathrm{mg} / \mathrm{kg} \mathrm{sc})$.

\section{DETERMINATION OF BLOOD ETHANOL LEVELS}

Tail blood $(20 \mu \mathrm{L})$ was collected at various time intervals and was immediately deproteinized in $180 \mu \mathrm{l}$ of $6.25 \%$ trichloroacetic acid. Ethanol content was determined enzymatically by the oxidation of ethanol to acetaldehyde coupled to the reduction of NAD to NADH (Sigma Diagnostics Kit 332-UV, Sigma).

\section{PRELIMINARY ASSESSMENT OF ETHANOL DEPENDENCE}

Two approaches were used to determine whether PCA rats developed signs of ethanol dependence. First, ethanol was withdrawn for periods of 1,3, or 8 days, with the ethanol solution being replaced by water; there was 1 week of ethanol availability between each withdrawal session. Voluntary ethanol consumption was monitored during the lights-on period, between 10:00 AM and noon, before ethanol withdrawal, and at the same time period after re-exposure to ethanol. The behavior of the animals was monitored for signs of ethanol withdrawal. In a second experiment, the effect of 3 days ethanol withdrawal was monitored $2 \mathrm{hr}$ after onset of the lights-off period.

STATISTICAL ANALYSIS

For statistical evaluation of the data, one- or two-way repeated measures ANOVAs, followed by the Newman-Keuls or Dunnet post-hoc tests, were used for multiple group comparisons. The unpaired Student's $t$ test for two group comparisons was also used; $\mathrm{p} \leq 0.05$ was considered to be statistically significant. The nonparametric Mann Whitney $\mathrm{U}$ test was used in the naloxone experiment, with $\mathrm{p} \leq 0.05$ considered to be statistically significant.

de Waele J-P, Audet R M, Rose C, Butterworth R F. The portacaval-shunted rat: a new model for the study of the mechanisms controlling voluntary ethanol consumption and ethanol preference? Alcohol Clin Exp Res. 1997-04;21(2):305310. 


\section{RESULTS}

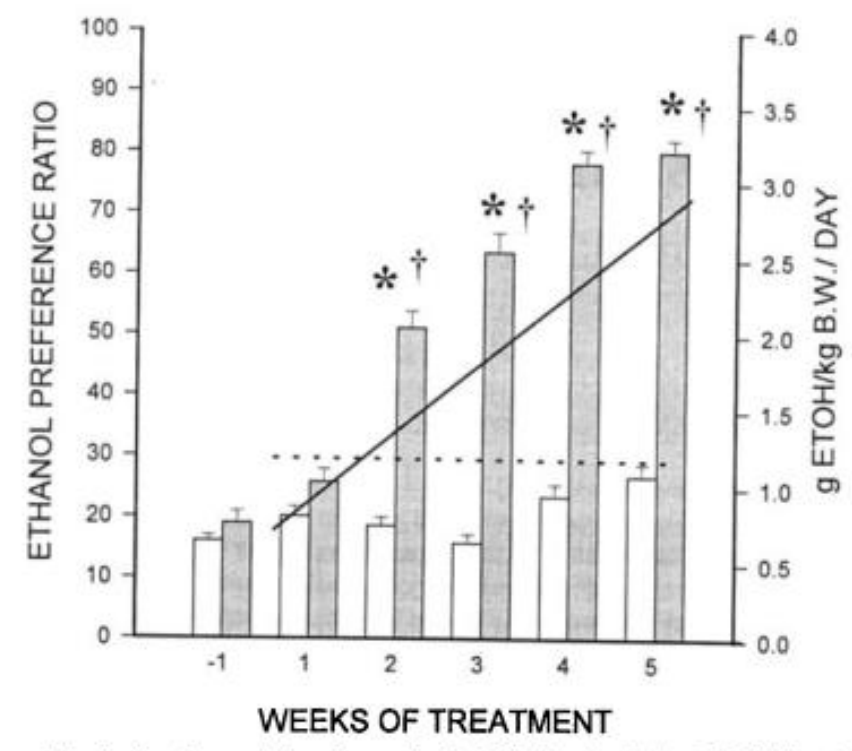

Fig. 1. Development of preference for the $5 \%$ ethanol solution in PCA (closed bars) but not sham-operated control (open bars) rats. Data represent the ratio of $5 \%$ ethanol solution to water as total liquid consumption and indicate the mean \pm SE of dally liquid intakes for 7 PCA and 6 sham-operated control rats, calculated for a consecutive 7-day period. "Significant difference from control $(p<0.01)$. †Significant difference from presurgery levels $(p<0.05)$. Lines represent the slope of the changes in the amount of ethanol consumed voluntarly after surgery in PCA (solid line) and sham-operated control (dotted line) rats. ETOH, ethanol; B.W., body weight.
Figure 1 shows the effects of PCA on voluntary ethanol consumption in the rat. PCA had no effect on the total volume of liquid consumed by the animals, which was maintained in the 72 to $81 \mathrm{ml} / \mathrm{kg}$ of body weight/day range for the duration of the experimental period. PCA induced an $11 \%$ decrease in body weight during the first 2 weeks postsurgery, which was followed by a gradual increase in body weight (data not shown), so that 2 weeks postsurgery, weight gain curves for the animals in the shunted group were not significantly different from sham-operated controls. Results of ethanol consumption are expressed as the ethanol preference ratio (volume of ethanol solution/total volume of fluid consumed) to assess the development of ethanol preference in PCA rats. This ratio was not significantly modified by sham operation. Before PCA surgery, $19 \pm 2 \%$ of the rats' total fluid intake constitued ethanol solution $(1.93 \pm 0.25 \mathrm{ml} / \mathrm{kg}$ of body weight/day). PCA led to an increase in this ratio to $78 \pm$ $2 \%(6.5 \pm 0.34 \mathrm{ml} / \mathrm{kg}$ of body weight/day), 4 weeks after surgery. A two-way ANOVA with treatment and time as independent variables demonstrated a significant effect of treatment $[\mathrm{F}(1,44)=50.12 ; \mathrm{p}<$

$0.001]$ and time $[F(4,44)=45 ; \mathrm{p}<0.001]$. These significant increases in ethanol preference ratio in PCA rats were manifested at weeks 2, 3, and 4 after PCA ( $\mathrm{p}<0.05$, NewmanKeuls test). There was no difference in ethanol consumption with time in sham-operated control rats. The level of ethanol consumption after PCA resulted in mean blood ethanol levels, measured $3 \mathrm{hr}$ after the onset of the lights-off period, of 40 $\mathrm{mg} \%$ (range: 3 to $158 \mathrm{mg} \%$ ). In parallel with the change in ethanol preference ratio, there was a significant increase in the total amount of ethanol consumed daily by PCA rats, which showed a positive correlation between volume of ethanol consumed and day of treatment (Spearman's $\mathrm{r}=0.648 ; \mathrm{p}<$ 0.001). Sham- operated control rats maintained a low but stable consumption of ethanol throughout the duration of the study (Spearman's $r=0.017 ; \mathrm{p}=0.789$ ) (Fig. 1).

The increase in ethanol consumption in rats after PCA took 6 to 7 days to develop, as demonstrated in Fig. 2. After a sharp

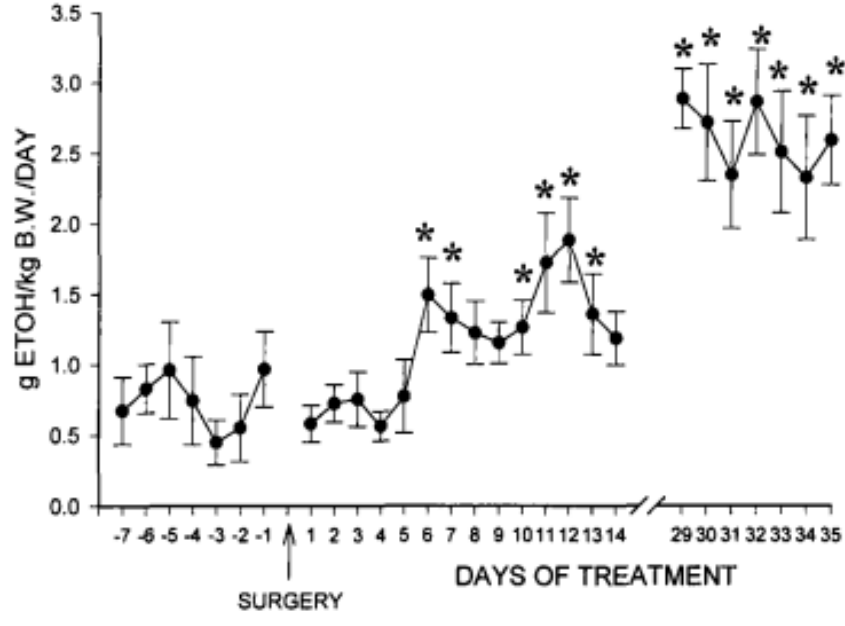

Fig. 2. Changes in the mean daily consumption of ethanol in seven PCA rats before PCA, during the first 2 weeks after surgery and in the fifth week after surgery. "Significant difference from presurgery levels $(p<0.05)$. ETOH, ethanol; B.W., body weight.

increase, ethanol consumption increased steadily for three consecutive weeks, as shown in Fig. 1. A one-way repeatedmeasures ANOVA followed by the Dunnet's test demonstrated a significant effect of time $[\mathrm{F}(22,160)=6.94 ; \mathrm{p}<0.001]$. Daily ethanol consumption by PCA rats then stabilized 4 weeks after surgery and remained at comparable levels for up to

de Waele J-P, Audet R M, Rose C, Butterworth R F. The portacaval-shunted rat: a new model for the study of the mechanisms controlling voluntary ethanol consumption and ethanol preference? Alcohol Clin Exp Res. 1997-04;21(2):305310. 
28 weeks. Similar levels of ethanol consumption were observed when ethanol concentration was doubled to $10 \%(3.51 \pm$ $0.37 \mathrm{~g} / \mathrm{kg}$ of body weight/day). At this time, the PCA rats consumed $59 \%$ of their ethanol during the lights-off period.
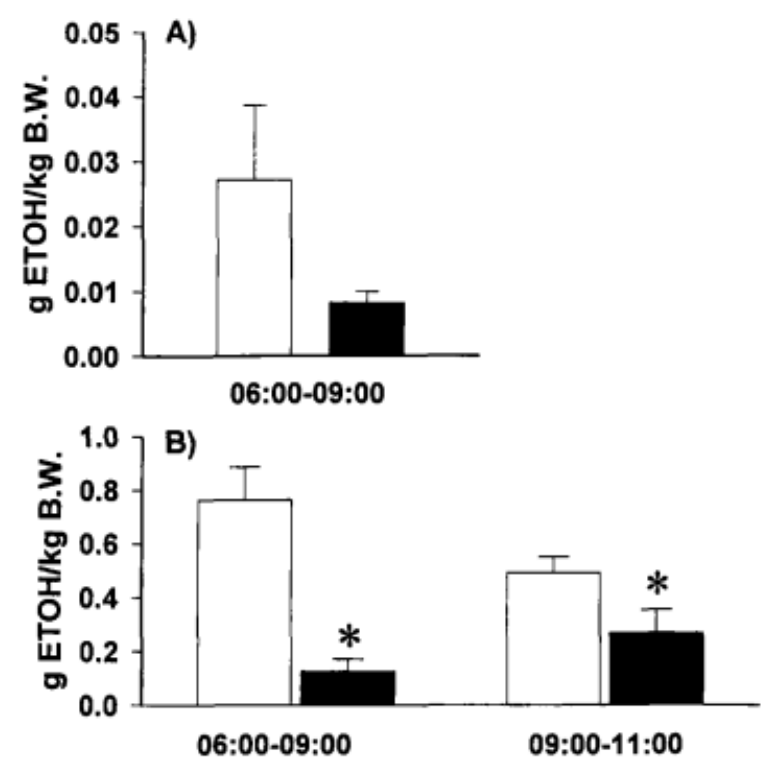

Fig. 3. Effect of naloxone administration $(5 \mathrm{mg} / \mathrm{kg}, \mathrm{sc})$ on the voluntary consumption of a $5 \%$ ethanol solution by sham-operated (A) and PCA $(B)$ rats. Data represent the amount of ethanol consumed (mean $\pm \mathrm{SE}$ for seven rats for each group) in the absence (open bars) and presence (closed bars) of naloxone over a 3-hr period, from the onset of the lights-off period, for the sham-operated rats and $5 \mathrm{hr}$ for the PCA rats. "Significant difference from saline treatment ( $p<$ 0.01). ETOH, ethanol; B.W., body weight.

Table 1. Effect of the Injection of Saline and Naloxone $(5 \mathrm{mg} / \mathrm{kg}, \mathrm{sc})$ on Locomotor Activity in PCA Rats

\begin{tabular}{cccc}
\hline & \multicolumn{3}{c}{ Total activity counts/hour } \\
\cline { 2 - 4 } Time & Control & \multicolumn{1}{c}{ Saline } & Naloxone \\
\hline Hour 1 & $409 \pm 85$ & $723 \pm 268$ & $407 \pm 140$ \\
Hour 2 & $466 \pm 87$ & $666 \pm 185$ & $437 \pm 115$ \\
Hour 3 & $557 \pm 225$ & $1113 \pm 251$ & $629 \pm 230$ \\
\hline
\end{tabular}

Locomotor activity of PCA rats was measured using an Animex activity monitor. Results are expressed as the number of beams crossed in $1 \mathrm{hr}$ under normal conditions and after the subcutaneous injection of saline or naloxone $(5 \mathrm{mg} / \mathrm{kg}$ body weight) on two consecutive days after 2 days of determination of normal (baseline) activity. Each value represents the mean \pm SE for six different animals. Neither saline nor naloxone had a significant effect on locomotor activity in PCA rats.

During withdrawal from ethanol, PCA rats showed signs of withdrawal such as teeth chattering, piloerection, vocalization, and aggressivity when handled, even though the animals had been handled daily for 7 weeks. After periods of withdrawal, there was an immediate relapse to increased voluntary ethanol consumption (Fig. $4 \mathrm{~A})$. When access to ethanol was resumed by replacing the water of one of the two drinking bottles by ethanol, all PCA rats resumed drinking within $1 \mathrm{~min}$, after a minimum of exploratory, mainly

de Waele J-P, Audet R M, Rose C, Butterworth R F. The portacaval-shun mechanisms controlling voluntary ethanol consumption and ethanol prefe 310 .
The effects of saline or naloxone administration $(5 \mathrm{mg} / \mathrm{kg} \mathrm{sc})$ on voluntary ethanol consumption in rats 5 weeks after PCA or sham operation are presented in Fig. 3. Administration of naloxone resulted in a significant ( $\mathrm{p}<0.01$, Student's $\mathrm{t}$ test) decrease in voluntary ethanol consumption in PCA rats, but not voluntary ethanol consumption in rats with PCA was still present $5 \mathrm{hr}$ after administration of naloxone, a period that represents The effects of saline and naloxone on locomotor activity in PCA rats are presented in Table 1. Locomotor activity increased in the hours after the onset of the dark period as expected. Although the animals were more active after saline injection than in basal conditions, this difference was not statistically significant ( $\mathrm{p}>$ 0.1 , Student's t test). Administration of naloxone $(5 \mathrm{mg} / \mathrm{kg} \mathrm{sc}$ ) however, had no effect on the locomotor activity of PCA rats.
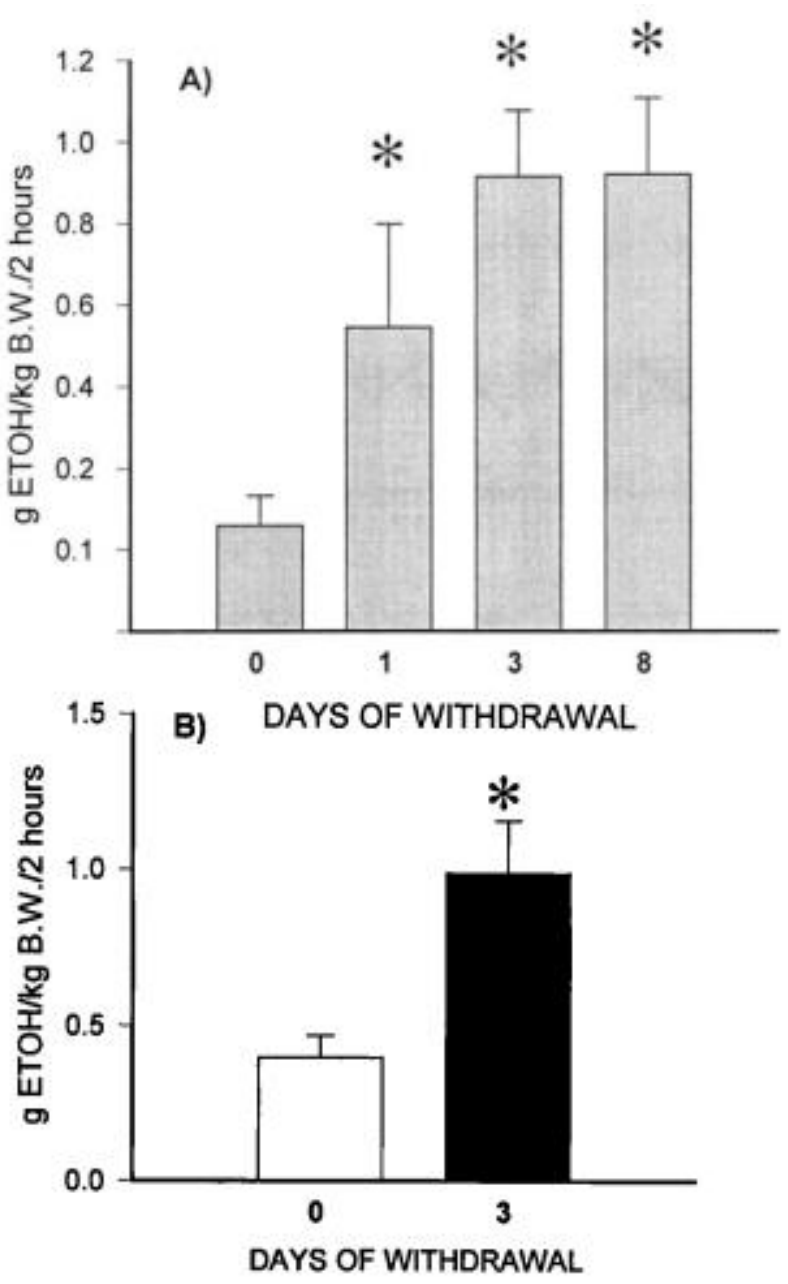

Fig. 4. (A) Effects of periods of ethanol deprivation on the amount of ethanol consumed by PCA rats in the $2 \mathrm{hr}$ atter reinstatement of the $10 \%$ ethanol bottle during the lights-on period. (B) Effects of 3 days of ethanol deprivation on the amount of ethanol oonsumed by PCA rats in the $2 \mathrm{rr}$ afior reinstatement of the $10 \%$ ethanol bottle during the lights-off period. Each bar represents the mean \pm SE for seven PCA rats. "Significant difference from control $(p<0.01)$. ETOH, ethanol; B.W., body weight. 
olfactory, behavior. A one-way ANOVA shows a significant effect of time of withdrawal $[F(3,40)=9.844, p<0.001]$. The effects of 3 and 8 days of withdrawal on ethanol consumption were similar ( $p>0.1$, Newman-Keuls), and blood ethanol levels reached $30 \pm 10 \mathrm{mg} \%$ at the end of the experimental period. Similar results were observed when ethanol consumption was measured during the first $2 \mathrm{hr}$ of the lights-off period (Fig. 4B). However, in both cases, there was no significant difference in the total volume of ethanol consumed in $24 \mathrm{hr}$ after withdrawal, compared with control values.

\section{DISCUSSION}

Results of the present study demonstrate that rats develop increased ethanol preference and increased consumption within 7 days of PCA, and that this increased voluntary ethanol consumption is sustained for several months. PCA rats orally selfadminister pharmacologically significant amounts of ethanol in a free-choice paradigm, producing blood ethanol levels up to $158 \mathrm{mg} \%$. They develop a preference for ethanol solution over drinking water and show behavioral signs suggestive of ethanol dependence. These results confirm and extend previous observations of increased ethanol consumption by rats after PCA. $(2,3)$ Because, in the present studies, the positions of ethanol and water bottles were alternated every day, development of a position preference bias in either the PCA or sham-operated control rats was eliminated. Both the ethanol preference ratio (defined as the percentage of total fluids consumed in the form of ethanol) and total ethanol consumption remained at low values in the sham-operated control group. In contrast, the volume of ethanol consumed by the PCA rats increased 2fold (from $0.77 \pm 0.26$ to $1.49 \pm 0.26 \mathrm{~g} / \mathrm{kg}$ of body weight/day), and the ethanol preference ratio increased 4-fold within 7 days of surgery. Mean voluntary ethanol consumption, with free access to water and food, by the selectively bred alcoholpreferring $\mathrm{P}$ and AA lines of rats, are reportedly in the $5 \mathrm{to} 7 \mathrm{~g}$ of ethanol $/ \mathrm{kg}$ of body weight/day range, a pattern of consumption that produces blood ethanol levels as high as $100 \mathrm{mg} \% \cdot(30,31)$. PCA rats consume less ethanol than these selectively bred ethanol-preferring rats, an observation that may result from the fact that genetic selection, either by inbreeding or by selective breeding, could induce an exacerbation of the selected trait (32), thus resulting in an exceedingly high amount of ethanol consumed by these animals. However, preliminary findings in the present study suggest that PCA rats do develop neurobehavioral signs consistent with physical dependence on ethanol suggest that PCA rats do develop neurobehavioral signs consistent with physical dependence on ethanol. For example, signs of withdrawal, corresponding to stages I1 to IV of withdrawal,(33) were observed when the ethanol solution was removed from PCA rats after 5 weeks of continuous ethanol exposure. Other indications of the possible development of physical dependence is the observation that PCA rats respond to a period of ethanol deprivation by a significant increase in ethanol consumption when unrestricted access is reinstated, a behavior previously reported both in ethanol-dependent animals(34) and in humans.(35) In the present study, the volume of ethanol consumed was monitored both between 10:00 AM and noon, when normal animals are inactive and when ethanol consumption would normally be minimal, and also during the $2 \mathrm{hr}$ after the onset of the lights-off period. The volume of ethanol consumed during the 2-hr period of lights-on, after reinstatement of ethanol exposure after 3 or 8 days of withdrawal, represents a 5- to 10-fold increase in the amount of ethanol normally consumed during the 10:00 AM to noon period. Similarly, the PCA rats respond to periods of withdrawal by a significantly higher level of ethanol consumption during the 2-hr period after reinstatement of ethanol, at the onset of the lights-off period after 3 days of withdrawal (Fig. 4B). In both cases, the increased ethanol consumption is restricted to the first $2 \mathrm{hr}$ after ethanol reinstatement, whereas no significant difference is observed in the total volume of ethanol consumed during the 24-hr period after reinstatement of ethanol, compared with the total ethanol intake for $24 \mathrm{hr}$ before withdrawal episodes. de Waele J-P, Audet R M, Rose C, Butterworth R F. The portacaval-shunted rat: a new model for the study of the mechanisms controlling voluntary ethanol consumption and ethanol preference? Alcohol Clin Exp Res. 1997-04;21(2):305310. 
The increase in voluntary ethanol consumption by rats after PCA may result from alterations in the activity of the endogenous opioid system(10). In favor of such a mechanism, previous reports describe significant increases in the density of $\delta$-opioid receptors in the nucleus accumbens of ethanol-naive PCA rats, compared with sham-operated controls (10), and increased densities of $\delta$-opioid receptors have been described in the nucleus accumbens of ethanol-naive alcohol-preferring AA rats, compared with alcohol-avoiding as well as in preliminary studies of the P rats compared with NP rats(37) and for the C57BL/6 (alcohol-preferring) compared with the DBN2 (alcohol-avoiding) inbred strains of mice.(38) The rewarding effects of ethanol and other drugs of abuse are mediated by the release of dopamine from the terminal fields of the A10 dopaminergic system located in the nucleus accumbens $(39,40)$ and ethanol-induced release of dopamine in the nucleus accumbens of Sprague-Dawley rats has been demonstrated in vivo. $(28,41)$ Microdialysis studies demonstrate that focal injection into the nucleus accumbens of [D-Ala-2] deltorphin II, a $\delta$-receptor (42) blocked the ethanol-induced release of dopamine in the nucleus accumbens, suggesting that $\delta$-receptors in the nucleus accumbens play a major role in the mediation of the positive-reinforcing effects of ethanol and thus in the control of voluntary ethanol consumption. These observations suggest that increased ethanol preference in PCA rats may be mediated, at least in part, by the endogenous opioid system, a suggestion that is further supported by the observation, in the present studies, of a significant reduction in ethanol intake after the administration of the nonspecific opioid receptor antagonist naloxone to these animals (Fig. 3). Previous studies suggest that naloxone induces a reduction in motor and one could argue that this may have been responsible for the decrease in ethanol consumption in the present study. However, this does not seem to be the case, because there were no differences in locomotor activity of PCA rats in the absence and presence of naloxone (Table 1), although there was a transitory increase in locomotor activity after the injection of saline alone, which probably resulted from injection stress. Thus, the observed decrease in voluntary ethanol consumption in PCA rats could be attributable to the blockade of opioid receptors, preventing the mediation of the positive-reinforcing effects of ethanol in these animals. Further studies using selective antagonists to both $\mathrm{p}$ - and S-opioid receptor subtypes are required to elucidate further the precise nature of the role of the opioid system in the modulation of increased ethanol consumption and preference by PCA rats.

The PCA rat model may facilitate the study of molecular mechanisms responsible for the initiation and development of ethanol preference and consumption in the same animal, irrespective of genetic predisposition. Furthermore, a careful examination of the biochemical changes occurring during the first 2 weeks after PCA, in relation to the development of increased voluntary ethanol consumption, may provide new insights into the role of neurotransmitter and/or neuropeptide systems involved in the development of alcohol preference and increased ethanol consumption. The observation that PCA induces an increase in voluntary ethanol consumption raises the possibility that some forms of excessive ethanol consumption may be the result of liver dysfunction, and that individuals with alcoholic or nonalcoholic liver disease may be susceptible to the development of hazardous drinking.

\section{REFERENCES}

1. Blei AT, Omary R, Butterworth RF Animal models of hepatic encephalopathy, in Neuromethods: Animal Models of Neurological Diseases. Clifton, NJ, Humana Press, 1992, p 183

2. Martin JR, Bircher J, Porchet H: Enhanced ethanol consumption following portal-systemic shunting in rats. Experientia 382314,1982

3. Martin JR, Porchet H, Buhler R, Bircher J: Increased ethanol consumption and blood ethanol levels in rats with portacaval shunts. Am J Physiol248:G287-G292, 1985

4. Sirnes TB: Voluntary consumption of alcohol in rats with cirrhosis of the liver. Q J Stud Alcohol 14:3-18, 1953

5. Grant KA, Samson HH: Induction and maintenance of ethanol self-administration without food deprivation in the rat. Psychopharmacology 86:475-479, 1985

de Waele J-P, Audet R M, Rose C, Butterworth R F. The portacaval-shunted rat: a new model for the study of the mechanisms controlling voluntary ethanol consumption and ethanol preference? Alcohol Clin Exp Res. 1997-04;21(2):305310. 
This is a post-peer-review, pre-copyedit version of an article published in Alcohol Clin Exp Res. The final authenticated version is available online at http://dx.doi.org/10.1111/j.1530-0277.1997.tb03765.x

6. Giguère JF, Butterworth RF: Amino acid changes in regions of the CNS in relation to function in experimental portal-systemic encephalop-athy. Neurochem Res 9:1039-1321, 1984

7. Bergeron M, Reader TA, Pomier Layrargues G, Butterworth RF Monoamines and metabolites in autopsied brain tissue from cirrhotic patients with hepatic encephalopathy. Neurochem Res 14:853-859, 1989

8. Bergeron M, Swain MS, Reader TA, Butterworth RF: Regional alterations of dopamine and its metabolites in rat brain following portacaval anastomosis. Neurochem Res 20:79-86, 1996

9. Zeneroli ML, Ventura E, Pinelli G, Casciarri I, Germini M, Cav aletti E, Tofanetti 0, Baraldi M: Opiate receptors and 0-endorphin levels in brain areas of dogs with portal-systemic encephalopathy. J Hepatol 1:619-627, 1985

10. de Waele J-P, Audet RM, Leong DK, Butterworth RF: Portacaval anastomosis induces region-selective alterations of the endogenous opioid system in the rat brain. Hepatology 24:895-901, 1996

11. Kalant H: Comparative aspects of tolerance to, and dependence on, alcohol, barbiturates and opiates, in Alcohol Intoxication and Withdrawal. New York, Plenum Press, 1977

12. Altshuler HL, Phillips PP, Feinhandler D A Alteration of ethanol self-administration by naltrexone. Life Sci 26:679-688, 1980

13. De Witte P: Naloxone reduces alcohol intake in a free-choice procedure even when both drinking bottles contain saccharin sodium or quinine substances. Neuropsychobiology 12:73-77, 1984

14. Kornet M, Goosen C, Van Ree JM: Effect of naltrexone on alcohol consumption during chronic alcohol drinking and after a period of imposed abstinence in free-choice drinking rhesus monkeys. Psychopharmacology 104:367-376, 1991

15. Froehlich JC, Zweifel M, Harts J, Lumeng L, Li TK: Importance of delta opioid receptors in maintaining high alcohol drinking. Psychopharmacology 103:467-472, 1991

16. L2 AD, Poulos CX, Quan B, Chow S: The effects of selective blockade of delta and mu receptors on ethanol consumption by C57BU6 mice in a restricted access paradigm. Brain Res 630:330-332, 1993

17. Volpicelli JR, Alterman AI, Hayashida M, OBrien CP: Naltrexone in the treatment of alcohol dependence. Arch Gen Psychiatry 49:876-880, 1992

18. O’Malley SS, Jaffe AJ, Chang G, Scottenfeld RS, Meyer RE, Rounsaville B: Naltrexone and coping skills therapy for alcohol dependence. A controlled study. Arch Gen Psychiatry 49:881-887, 1992

19. Keith LD, Crabbe JC, Robertson LM, Kendall JW: Ethanol-stimulated endorphin and corticotropin secretion in vitro. Brain Res 367:222- 229, 1986

20. Gianoulakis C: Characterization of the effects of acute ethanol administration on the release of 6-endorphin peptides by the rat hypothalamus. Eur J Pharmacol 180:21-29, 1990

21. de Waele J-P, Papachristou D, Gianoulakis C: The alcohol-preferring C57BU6 mice present an enhanced sensitivity of the hypothalamic 6-endorphin system to ethanol than the alcohol-avoiding DBN2 mice. J Pharmacol Exp Ther 261:788-794, 1992

22. de Waele J-P, Gianoulakis C Effects of single and repeated expo- sures to ethanol on hypothalamic 6-endorphin and CRH release by the C57BU6 and DBN2 strains of mice. Neuroendocrinology 570:700-709, 1993

23. de Waele J-P, Kiianmaa K, Gianoulakis C Spontaneous and eth- anol-stimulated in vitro release of $\beta$-endorphin by the hypothalamus of AA and ANA rats. Alcohol Clin Exp Res 18:1468-1473, 1994

24. Thornton JR, Losowsky MS: Plasma methionine enkephalin con- centration and prognosis in primary biliary cirrhosis. Br Med J 2971241- 1242, 1988

de Waele J-P, Audet R M, Rose C, Butterworth R F. The portacaval-shunted rat: a new model for the study of the mechanisms controlling voluntary ethanol consumption and ethanol preference? Alcohol Clin Exp Res. 1997-04;21(2):305310 . 
This is a post-peer-review, pre-copyedit version of an article published in Alcohol Clin Exp Res. The final authenticated version is available online at http://dx.doi.org/10.1111/j.1530-0277.1997.tb03765.x

25. Thornton JR, Losowsky MS: Plasma /3-endorphin in cirrhosis and renal failure. Gut 32:306-308, 1991

26. Zeneroli ML. Baraldi M. Ventura E. Zanoli P, Vezzeli C, Russo AM: Beta-endorphin and opiate receptor changes in acute and chronic models of hepatic encephalopathy, in Hepatic Encephalopathy: Patho- physiology and Treatment. Clifton. NJ. Humana Press, 1988

27. Panerai AE. Salerno F. Baldissera F. Martini A. Di Giulio AM, Mantegazza P: Brain $\beta$-endorphin concentrations in experimental chronic liver disease. Brain Res 247:188-190, 1982

28. Di Chiara G. Imperato A: Drugs abused by humans preferentially increase synaptic dopamine concentrations in the mesolimbic system of freely moving rats. Proc Natl Acad Sci USA 855274-5278, 1988

29. Buttenvorth RF, Girard G, Gigukre JF: Regional differences in the capacity for ammonia removal by brain following portocaval anastomosis. J Neurochem 51:486-490, 1988

30. Li TK, Lumeng L, McBride WJ, Waller MB: Progress toward a voluntary oral consumption model of alcoholism. Drug Alcohol Depend 4 45-60, 1979

31. Eriksson K Alcohol consumption and blood alcohol in rat strains selected for their behavior towards alcohol, in Biological Aspects of Alcohol Consumption, vol 20. Helsinki, Finnish Foundation for Alcohol Studies, 1972

32. Falconer DS: Introduction to Quantitative Genetics. Hong Kong, Longman Scientific and Technical, 1989

33. Waller MB, McBride WJ, Lumeng L, Li T K Induction of depen- dence on ethanol by free-choice drinking in alcohol-preferring rats. Phar- macol Biochem Behav 16:501-507, 1982

34. Sinclair JD, Senter R: Increased preference for ethanol in rats following alcohol deprivation. Psycho1 Sci 8:11-12, 1967

35. Burish T, Maisto SA. Cooper AM, Sobell MB: Effects of voluntary short-term abstinence from alcohol on subsequent drinking patterns of college students. J Stud Alcohol 421013-1020, 1981

36. de Waele J-P, Kiianmaa K, Gianoulakis C Distribution of the mu and delta opioid binding sites in the brain of the alcohol-preferring AA and alcohol-avoiding ANA lines of rats. J Pharmacol Exp Ther 275518- 527, 1995

37. McBride WJ, Chernet E, Guan X-M, Lumeng L, Li TK: Densities of opioid receptors in the CNS of alcohol-preferring (P) and nonpreferring (NP) lines of rats. SOC Neurosci Abstr 16:434, 1990 (Abstr.)

38. de Waele J-P, Gianoulakis C: Autoradiographic localization of the $\mathrm{p}$ and $\mathrm{S}$ receptors in the brain of mice selected for their differences in voluntary ethanol consumption. SOC Neurosci Abstr 18:269, 1992 (abstr.)

39. Routtenberg A Self-stimulation pathways: Origins and termina- tions-A three stage technique, in Brain-Stimulation Reward. Amsterdam, Elsevier/North Holland Biomedical Press, 1976

40. Wise RA, Bozarth MA: Action of drugs of abuse on brain reward systems: An update with specific attention to opiates. Pharmacol Biochem Behav 17239-243, 1982

41. Wosniak KM, Pert A, Mele A, Linnoila M: Focal application of alcohols elevates extracellular dopamine in rat brain: A microdialysis study. Brain Res 54031-40, 1991

42. Acquas E, Meloni M, Di Chiara G: Blockade of 8-opioid receptors in the nucleus accumbens prevents ethanol-induced stimulation of dopa- mine release. Eur J Pharmacol 230339-241, 1993

43. File SE: Naloxone reduces social and exploratory activity in the rat. Psychopharmacology 71:41-44, 1980

de Waele J-P, Audet R M, Rose C, Butterworth R F. The portacaval-shunted rat: a new model for the study of the mechanisms controlling voluntary ethanol consumption and ethanol preference? Alcohol Clin Exp Res. 1997-04;21(2):305310. 